between PCV with type $2 \mathrm{CNV}$ and pure fibrinous exudation. Further studies are needed to determine the accurate diagnosis and proper treatment for patients with type $2 \mathrm{CNV}$ associated with PCV.

Br J Ophthalmol 2007;91:1103-1104. doi: 10.1136/bjo.2007.116160

Correspondence to: Tomohiro lida, Department of Ophthalmology, Fukushima Medical University School of Medicine, 1 Hikarigaoka, Fukushima, Japan; iidat@fmu.ac.jp

Competing interest: None.

\section{REFERENCES}

1 Yannuzzi LA, Sorenson J, Spaide RF, et al. Idiopathic polypoidal choroidal vasculopathy (IPCV). Retina 1990;10:1-8.

2 Kleiner RC, Brucker AJ, Johnston RL. The posterior uveal bleeding syndrome. Retina 1990;10:9-17.

3 Stern RM, Zegarra H, Kleiner RC, et al. Multiple recurrent serosanguineous retinal pigment epithelial detachments in black women. Am J Ophthalmol 1985; 100:560-69

4 Perkovich BT, Zakov ZN, Berlin LA, et al. An update on multiple recurrent serosanguineous retinal pigment epithelial detachments in black women. Retina 1990;10:18-26.

5 Spaide RF, Yannuzzi LA, Slakter JS, et al. Indocyanine green videoangiography of idiopathic polypoidal choroidal vasculopathy. Retina 1995; 15:100-10.

6 Yannuzzi LA, Ciardella A, Spaide RF, et al. The expanding clinical spectrum of idiopathic polypoidal choroidal vasculopathy. Arch Ophthalmol 1997;115:478-85.

7 Yuzawa M, Mori R, Kawamura A. The origins of polypoidal choroidal vasculopathy. Br J Ophthalmol 2005;89:602-7.

8 Uyama M, Matsubara T, Fukushima l, et al. Idiopathic polypoidal choroidal vasculopathy in Japanese patients. Arch Ophthalmol 1999;117:1035-42.

9 Yannuzzi LA, Wong DWK, Sforzolini BS, et al. Polypoidal choroidal vasculopathy and neovascularized age-related macular degeneration. Arch Ophthalmol 1999; 117:1503-10.
10 Sho K, Takahashi K, Yamada H, et al. Polypoidal choroidal vasculopathy. Incidence, demographic features, and clinical characteristics. Arch Ophthalmol 2003;121:1392-6.

11 Singerman LJ, Brucker AJ, Jampol LM, et al. Neovascular age-related macular degeneration: roundtable. Retina 2005;25:S1-22.

12 Ahuja RM, Stanga PE, Vingerling JR, et al. Polypoidal choroidal vasculopathy in exudative and haemorrhagic pigment epithelial detachments. Br J Ophthalmol 2000;84:479-84.

13 Lafaut BA, Leys AM, Snyers B, et al. Polypoidal choroidal vasculopathy in Caucasians. Graefe's Arch Clin Exp Ophthalmol 2000;238:752-9.

14 Scassellati-Sforzolini B, Mariotti C, Bryan R, et al. Polypoidal choroidal vasculopathy in Italy. Retina 2001;21, 121-5.

15 Kwok AKH, Lai TYY, Chan CWN, et al. Polypoidal choroidal vasculopathy in Chinese patients. Br J Ophthalmol 2002;86:892-7.

16 Wen F, Chen C, Wu D, et al. Polypoidal choroidal vasculopathy in elderly Chinese patients. Graefe's Arch Clin Exp Ophthalmol 2004;242:625-9.

17 Yoshimura N. Polypoidal choroidal vasculopathy. [in Japanese] Folia Ophthalmol Jpn 2004:55:155-72.

18 Maruko I, lida $T$, Saito $M$, et al. Clinical characteristics of exudative age-related macular degeneration in Japanese patients. Am J Ophthalmol. In press.

19 Moorthy RS, Lyon AT, Rabb MF, et al. Idiopathic polypoidal choroidal vasculopathy of the macula. Ophthalmology 1998;105:1380-5.

20 Uyama M, Wada M, Nagai Y, et al. Polypoidal choroidal vasculopathy: natural history. Am J Ophthalmol 2002;133:639-48.

21 Spaidey RF, Donsoff I, Lam DL, et al. Treatment of polypoidal choroidal vasculopathy with photodynamic therapy. Retina 2002;22:529-35.

22 Lee SC, Seong YS, Kim SS, et al. Photodynamic therapy with verteporfin for polypoidal choroidal vasculopathy of the macula. Ophthalmologica 2004;218:193-201.

23 Chan WM, Lam DSC, Lai TYY, et al. Photodynamic therapy with verteporfin for symptomatic polypoidal choroidal vasculopathy. One-year results of a prospective case series. Ophthalmology 2004;111:1576-84.

24 Silva RM, Figueira J, Cachulo ML, et al. Polypoidal choroidal vasculopathy and photodynamic therapy with verteporfin. Graefe's Arch Clin Exp Ophthalmol 2005;243:973-9.
25 Treatment of Age-related Macular Degeneration With Photodynamic Therapy (TAP) Study Group. Photodynamic therapy of subfoveal choroidal neovascularization in age-related macular degeneration with verteporfin: two-year results of 2 randomized clinical trials - TAP report 2. Arch Ophthalmol 2001;119:198-207.

26 Verteporfin in Photodynamic Therapy Study

Group. Verteporfin therapy of subfoveal choroidal neovascularization in age-related macular degeneration: two-year results of a randomized clinical trial including lesions with occult with no classic choroidal neovascularization - verteporfin in photodynamic therapy report 2. Am J Ophthalmol 2001;131:541-60.

27 MacCumber MW, Dastgheib K, Bressler NM, et al. Clinicopathologic correlation of the multiple recurrent serosanguineous retinal pigment epithelial detachments syndrome. Retina 1994;14:143-52.

28 Kuroiwa S, Tateiwa H, Hisatomi T, et al. Pathological features of surgically excised polypoidal choroidal vasculopathy membranes. Clin Experiment Ophthalmol 2004;32:297-302

29 Shiraga F, Matsuo T, Yokoe S, et al. Surgical treatment of submacular hemorrhage associated with idiopathic polypoidal choroidal vasculopathy. Am J Ophthalmol 1999; 128: 147-54.

30 Terasaki H, Miyake Y, Suzuki T, et al. Polypoidal choroidal vasculopathy treated with macular translocation: clinical pathological correlation. Br J Ophthalmol 2002;86:321-7.

31 Nakajima M, Yuzawa M, Shimada $H$, et al. Correlation between indocyanine green angiographic findings and histopathology of polypoidal choroidal vasculopathy. Jpn J Ophthalmol 2004;48:249-55.

32 Gass JDM. Biomicroscopic and histopathologic considerations regarding the feasibility of surgical excision of subfoveal neovascular membranes. Am J Ophthalmol 1994;118:285-98.

33 Rogers AH, Martidis A, Greenberg PB, et al. Optical coherence tomography findings following photodynamic therapy of choroidal neovascularization. Am J Ophthalmol 2002;134:566-76

34 Otsuji T, Tsumura A, Takahashi K, et al. Evaluation of cases of polypoidal choroidal vasculopathy showing classic choroidal neovascularization in their natural course. [in Japanese] J Jpn Ophthalmol Soc, 2006;1 10:454-61.

35 Tamura H, Tsujikawa A, Otani A, et al. Polypoidal choroidal vasculopathy appearing as classic choroidal neovascularisation on fluorescein angiography. Br J Ophthalmol 2007;91:1152-9.

\title{
Polypoidal choroidal vasculopathy
}

\section{Fumihiko Mori, Shuichiro Eguchi}

\section{From the viewpoint of an Asian ophthalmologist}

$P^{i}$ olypoidal choroidal vasculopathy (PCV) has been recognised for almost two decades. In 1990, Yannuzzi and colleagues first described idiopathic polypoidal choroidal vasculopathy (IPCV) macular disorder-a choroidal vasculopathy that causes haemorrhagic and exudative macular degeneration-in 11 patients. ${ }^{1}$ The patients had peculiar polypoidal subretinal vascular lesions associated with serous and haemorrhagic detachments of the retinal pigment epithelium (RPE). In the late 1990s, Yannuzzi and colleagues expanded the clinical spectrum of IPCV and established the concept of PCV. ${ }^{2}$

In 1995, Spaide and colleagues identified the precise choroidal abnormalities associated with PCV and examined them using indocyanine green angiography
(IA). ${ }^{4}$ IA showed two basic choroidal vascular changes: a branching network of vessels in the inner choroid and polypoidal vascular dilations at the border of the network of vessels. IA confirmed the definitive diagnosis of PCV. In 1999, using optical coherence tomography (OCT), Iijima and colleagues showed that on images of the inner choroid in eyes with PCV orange-red lesions protruded anteriorly. ${ }^{5}$ These lesions had a sharper peak than serous RPE detachments in the subretina, suggesting that polypoidal vascular lesions in eyes with PCV lie beneath Bruch's membrane and are covered anteriorly by the RPE and Bruch's membrane. $^{6}$ IA and OCT, relatively new diagnostic devices, are useful for understanding the pathophysiology and for diagnosing PCV. However, the cause and the pathogenesis of PCV are not clearly known. 
In 1999, Uyama and colleagues described the nature and clinical features of PCV in 32 Japanese patients. ${ }^{7}$ IA showed branching vascular networks with polypoidal dilations at the network terminals beneath the RPE in all patients. These lesions were mostly in the macula (94\%), with a few in the peripapillary area. The authors concluded that PCV in Japanese patients differs from that in US patients. In 2002, the same investigators clarified the long-term natural history of PCV. ${ }^{8}$ Fourteen eyes of 12 untreated Japanese patients with PCV were followed prospectively for at least 2 years after the first visit. The authors concluded that PCV is a chronic disease of long duration, and the patients had varying courses. Fifty per cent of the patients had a favourable course; in the other 50\%, the disorder persisted for a long time with occasional episodes of bleeding and leakage, resulting in macular degeneration and visual loss. In 2005, the Japanese Study Group of Polypoidal Choroidal Vasculopathy reported the criteria for this disorder in Japanese patients, ${ }^{9}$ based on a fundus examination, IA findings or both. Definitive cases meet at least one of the following criteria: 1) protruding elevated orange-red lesions observed by fundus examination and 2) characteristic polypoidal lesions seen on IA. Probable cases meet at least one of the follwing criteria: 1) only an abnormal vascular network is seen in IA and 2) recurrent haemorrhagic and/or serous detachments of the RPE are observed.

On fluorescein angiography, eyes with PCV have primarily occult choroidal neovascularisation (CNV) because most components of PCV are beneath the RPE. However, 9\% of eyes with PCV in Japanese patients have classic CNV on fluorescein angiography. ${ }^{10}$ Otsuji and colleagues evaluated eight eyes of eight Japanese patients with PCV with classic $\mathrm{CNV}$ on fluorescein angiography, using IA and OCT. ${ }^{11}$ All patients had greyish subretinal exudates, which were considered fibrinous. The authors concluded that both type $2 \mathrm{CNV}$ and PCV with fibrin without CNV are present in patients with PCV showing classic CNV. It is important to determine if type $2 \mathrm{CNV}$ is present in eyes with PCV, because the visual prognosis in the presence of type $2 \mathrm{CNV}$ is worse in PCV.

In this issue of the BJO (see page 1152), Tamura and colleagues retrospectively reviewed the visual prognosis and ocular characteristics of 38 eyes with PCV of Japanese patients that appear to have classic CNV on fluorescein angiography. ${ }^{12}$ OCT showed subretinal material with moderate reflectivity that corresponded in location to classic CNV in all cases. At the final visit, the subretinal material resolved completely in 14 eyes but resolved incompletely in 24 eyes after photodynamic therapy (PDT). The visual acuity in the group with resolved lesions was significantly better than in the group in which the lesions persisted at the final visit. The authors hypothesised that eyes with persistent lesions have type $2 \mathrm{CNV}$, and the eyes with resolved lesions have deposition of pure fibrous tissue without CNV. The subretinal material seen before treatment was more frequent in the subfovea in the group with persistent lesions and adjacent to polypoidal lesions in the group with resolved lesions. The authors suggested that although it is difficult to discriminate type $2 \mathrm{CNV}$ from pure fibrin deposition before treatment, type $2 \mathrm{CNV}$ is seen more often in the subfovea and is typically separate from the polypoidal lesions.

Chan and colleagues determined the efficacy of PDT with verteporfin (Visudyne, Novartis, Switzerland) as a treatment for PCV in Asian patients. ${ }^{13}$ Stable or improved vision was achieved in $21(95 \%)$ of the 22 eyes at the 1 year follow-up. Severe visual loss due to massive subretinal haemorrhage occurred in one eye. This report showed that PDT is an effective treatment for PCV. Tamura and colleagues reported that stable or improved vision was achieved in 18 (75\%) of the 24 eyes with PCV with type $2 \mathrm{CNV}$ at the final visit. The authors suggested that the treatment effect is limited in eyes with PCV with type 2 CNV.

Recently, the MARINA and ANCHOR studies reported that intravitreal administration of ranibizumab (Lucentis, Genentech, USA), a recombinant, humanised, monoclonal antibody Fab that neutralises all active forms of vascular endothelial growth factor A, prevented vision loss and improved the mean visual acuity with low rates of serious adverse events in patients with CNV secondary to age-related macular degeneration. ${ }^{14}{ }^{15}$ The efficacy and safety of this new treatment for PCV should be evaluated. I believe that the diagnosis and treatment of PCV require management by a medical retina specialist using new diagnostic devices and therapies such as fluorescein angiography, IA, OCT, and PDT.

Br J Ophthalmol 2007;91:1104-1105.

doi: 10.1136/bjo.2007.116178

....................

Authors' affiliations

Fumihiko Mori, Shuichiro Eguchi, Eguchi Eye Hospital, 7-13 Suehiro-cho Hakodate, Japan

Correspondence to: Fumihiko Mori, Eguchi Eye Hospital, 7-13 Suehiro-cho Hakodate, Japan; fmorichan@yahoo.co.jp

Competing interests: None.

\section{REFERENCES}

1 Yannuzzi LA, Sorenson J, Spaide RF, et al. Idiopathic polypoidal choroidal vasculopathy (IPCV). Retina 1990;10:1-8.

2 Yannuzzi LA, Ciardella A, Spaide RF, et al. The expanding clinical spectrum of idiopathic polypoidal choroidal vasculopathy. Arch Ophthalmol 1997; 115:478-85.

3 Yannuzzi LA, Wong DWK, Sforzolini BS, et al. Polypoidal choroidal vasculopathy and neovascularized age-related macular degeneration. Arch Ophthalmol 1999; 11:1503-10.

4 Spaide RF, Yannuzzi LA, Slakter JS, et al. Indocyanine green videoangiography of idiopathic polypoidal choroidal vasculopathy. Retina 1995; 15:100-10.

5 lijima H, Imai M, Gohdo T, et al. Optical coherence tomography of idiopathic polypoidal choroidal vasculopathy. Am J Ophthalmol 1999;127:301-5.

6 lijima $\mathrm{H}$, lida T, Imai $M$, et al. Optical coherence tomography of orange-red subretinal lesions in eyes with idiopathic polypoidal choroidal vasculopathy. Am J Ophthalmol 2000;129:21-6.

7 Uyama M, Matsubara T, Fukushima I, et al. Idiopathic polypoidal choroidal vasculopathy in Japanese patients. Arch Ophthalmol 1999; 117:1035-42

8 Uyama M, Wada M, Nagai Y, et al. Polypoidal choroidal vasculopathy: Natural history. Am J Ophthalmol 2002; 133:639-48.

9 Japanese Study Group of Polypoidal Choroidal Vasculopathy. Criteria for diagnosis of polypoidal choroidal vasculopathy. J Jpn Ophthalmol Soc 2005; 109:417-27

10 Sho K, Takahashi K, Yamada H, et al. Polypoidal choroidal vasculopathy: incidence, demographic features, and clinical characteristics. Arch Ophthalmol 2003;121:1392-6.

11 Otsuji T, Tsumura A, Takahashi K, et al. Evaluation of cases of polypoidal choroidal vasculopathy showing classic choroidal neovascularization in their natural course. J Jpn Ophthalmol Soc 2006;110:454-61

12 Tamura H, Tsujikawa A, Otani A, et al. Polypoidal choroidal vasculopathy appearing as classic choroidal neovascularisation on fluorescein angiography. Br J Ophthalmol 2007;91:1152-9.

13 Chan WM, Lam DSC, Lai TY, et al. Photodynamic therapy with verteporfin for symptomatic polypoidal choroidal vasculopathy. Ophthalmology 2004; 111:1576-84.

14 Rosenfeld PJ, Brown DM, Herier JS, MARINA Study Group, et al. Ranibizumab for age-related macular degeneration. N Engl J Med 2006;355:1419-31.

15 Brown DM, Kaiser PK, Michels M, ANCHOR Study Group, et al. Ranibizumab versus verteporfin for neovascular age-related macular degeneration. N Engl J Med 2006;355: 1432-44. 